\title{
Acute And Sub Chronic Toxicity Of Tridax Procumbens In Experimental Animals
}

\author{
Abubakar A., ${ }^{*}$ Ogbadoyi E. O. ${ }^{2}$, Okogun J. I. ${ }^{3}$, Gbodi T. I., ${ }^{4}$ Tifin U. F. ${ }^{5}$ \\ ${ }^{1}$ Nigerian Institute for Trypanosomiasis Research, P. M. B. 1147, Birnin Kebbi, Kebbi State, Nigeria \\ ${ }^{2}$ Global Institute for Bioexploration, Federal University of Technology, Minna/Department of Biochemistry, \\ Federal University of Technology, Minna, Niger State, Nigeria. \\ ${ }^{3}$ Department of Traditional Medicine and Medicinal Plant Research, National Institute for Pharmaceutical \\ Research and Development, Abuja, Nigeria \\ ${ }^{4}$ Department of Biochemistry, Ibrahim Badamasi Babangida University, Lapai, Niger State, Nigeria \\ ${ }^{5}$ General Hospital Minna, Niger state, Nigeria
}

\begin{abstract}
The studies focused on the toxicity of ethyl acetate extract of Tridax procumbens (Compositeae) reported to have various pharmacological effects, antimicrobial activities against gram-positive and gramnegative bacteria and to stimulate wound healing. The acute toxicity was carried out using the method of Lorkes. In the subchronic study, rats received intraperitoneally T. procumbens at doses of 50, 100, 200, 400, and $800 \mathrm{mg} / \mathrm{kg}$ for 14 consecutive days. Serum biochemical parameters, haematological analysis and histopathology of liver and kidneys were assessed after the last administration. After acute administration, signs of toxicity observed include salivation, rubbing at site of application, nose and mouth on the floor of the cage and restlessness. The $L D_{50}$ of the extract was $2100 \mathrm{mg} / \mathrm{kg}$ body weight, and all the survived animals gained body weight and organ / body weight ratio as compared to the untreated control $(P<0.05)$. In sub chronic study, all the animals gained body weight and organ / body weight ratio. Liver and kidney function tests were assessed by determining levels of some serum biochemical parameters (sodium, potassium, transaminases, urea, total protein and glucose). There were significant decrease in glucose levels $(P<0.05)$ and significant increase in Alanine amino transaminase (ALT) and decrease in Aspartate amino transaminase (AST) activities with $800 \mathrm{mg} / \mathrm{kg}$ producing highest effect $(P<0.05)$. Alkaline phosphatase $(A L P)$ activity, urea, total proteins and electrolyte levels were not affected significantly $(P>0.05)$. The ethyl acetate extract treated rats increased the Packed Cell Volume (PCV), erythrocyte and leucocyte count $(P>0.05)$ compared to untreated control. The results of histopathological studies showed that ethyl acetate extract had endothelial toxicity at high dose level destroying the blood vessels leading to haemorrhage as indicated by haemosiderin deposition throughout the entire kidney and liver parenchyma. It was concluded that the extract at higher doses had some specific toxic effect which was corroborated by the result of histopathology where there was haemosiderin deposition.
\end{abstract}

Key Words: Toxicity, Tridax procumbens, Ethyl acetate extract, Mice, Rats

\section{Introduction}

Plant derived products have been used for medicinal purposes for centuries. At present, it is estimated that about $80 \%$ of the world population relies on botanical preparations as medicines to meet their health needs (Shri, 2003). Herbs and spices are generally considered safe and proved to be effective against certain ailments. While literature has documented severe toxic reactions from the use of herbs on many occasions, the potential toxicity of herbs has not been recognized by the general public or by professional groups of traditional medicine (Deng, 1994; O'Hara et al 1998). Patients are often unaware of important similarities and differences between medicinal herbs and approved medications, some mistakenly think of herbs as natural alternatives to chemicals, failing to recognize that herbs are composed of bioactive chemicals some of which may be toxic (Tyler, 1994). Many xenobiotics are capable of causing some degree of liver injury (Bass and Ockner, 1996). The liver is prone to xenobiotic-induced injury because of its central role in xenobiotic metabolism (Jones, 1996). The Kidney is highly susceptible to toxicants because a high volume of blood flows through it and it filters large amounts of toxins which can concentrate in the kidney tubules (Emily, 2007). Nephrotoxicity can result in systemic toxicity causing decreased ability to excrete body wastes, inability to maintain body fluid, electrolyte balance and decreased synthesis of essential hormones (Emily, 2007).

Tridax procumbens is known for several potential therapeutic activities like antiviral, antibiotic efficacies; wound healing activity, insecticidal and anti-inflammatory activity (Suseela et al., 2002). The plants has been extensively used in Ayurvadic system of medicine for various ailments and is shown to possess significant anti inflammatory, hepato-protective, wound healing and antimicrobial properties (Diwan et al., 
1989; Pathak et al., 1991; Saraf et al., 1991; Udupa et al., 1991; Perumal et al., 1999; and Taddei and Rosas 2000). The present study was undertaken to determine the toxicity of the ethyl acetate extract of T. procumbens.

\section{1) Animals}

\section{Methodology}

The experimental animals used in this study were Swiss albino mice of both sexes each weighing 20$30 \mathrm{~g}$ and Albino rats weighing 50-80g. The animals were randomly distributed into cages with free access to water and food except for the short fasting period before oral administration of doses of extract. All animals (mice) were maintained on a $12 \mathrm{~h}$ light/dark cycle, at constant temperature and humidity. The study was approved by the institution's animal Ethical Committee.

\section{2) Plant Materials}

The aerial part of Tridax procumbens were collected in the months of May and June within and around Kaduna Vom, Plateau State and Federal University of Technology Minna, Bosso campus, Niger State, Nigeria. The voucher number, NIPRD/H/6155, was deposited at the herbarium of National Institute for Pharmaceutical Research and Development, Idu, Abuja, Nigeria. About $1 \mathrm{~kg}$ each of the whole Tridax procumbens was freshly obtained, washed with running tap water and dried at room temperature to a constant weight. The dried plant samples were ground into powder form using mortar and pestle and the powdered samples were stored in clean polythene bags until required for use.

\section{3) Preparation of Crude Extracts}

The extracts were prepared using the method described by Ogbadoyi et al., (2007). In this method, fifty grams $(50 \mathrm{~g})$ of the dried powdered samples of Tridax procumbens was first defatted in hexane and then extracted under reflux with $400 \mathrm{ml}$ of ethyl acetate for 2 hrs. Extract was filtered hot using muslin cloth and concentrated using rotatory evaporator. The extract was finally dried in steam bath and transferred into sterile sample bottles for storage at refrigerated temperature until when required for use.

\section{4) Phytochemical Analysis}

The crude extracts were screened for the presence of alkaloids, saponins, sterols, tannins, flavonoids, phenols, carbohydrate, tarpenes, Resins, and Anthraquinones using simple chemical test as variously described by Evans (1989) and Sofowora (1993).

\section{5) Acute Toxicity Studies of Ethyl Acetate Crude Extract}

The acute toxicity of the ethyl acetate extract of Tridax procumbens was evaluated using the method described by Lorke (1983) with slight modification. In the first phase, nine mice randomly divided into three groups of three mice per group and each was given 10, 100 and $1000 \mathrm{mg}$ extract/kg body weight intraperitoneally respectively. In the second phase of the study, the procedure was repeated using another set of nine mice randomly divided into three groups of three mice each, given 1600, 2900 and $5000 \mathrm{mg}$ extract $/ \mathrm{kg}$ body weight, respectively. All the extracts were dissolved in Dimethyl sulphoxide (DMSO) and physiological saline combination before administration. Another fresh set of three mice were given DMSO in physiological saline to serve as the control and all the mice were kept under same conditions and observed for the first critical $4 \mathrm{~h}$, subsequently for $72 \mathrm{~h}$ and thereafter for 14 days. The signs of toxicity such as physical activity and general appearance, paw-licking, salivation, stretching, Gastrointestinal Signs: Dropping (Faeces), rubbing of nose on the floor and wall of cage, sedation, coma, convulsion and death. The number of deaths in each group within 24 $\mathrm{h}$ was recorded and the final median lethal dose $\left(\mathrm{LD}_{50}\right)$ was calculated as the geometric mean of the highest nonlethal dose (with no deaths) and the lowest lethal dose (where deaths occurred).

\section{6) Short Term Toxicity Studies of T. procumbens}

The short-term toxicity studies of the extract were evaluated according to the format described by Wilson et al., (2001). Six groups, (A - F), consisting of five Wister rats each, were set up. Groups A - E animals were administered intraperitoneally with 50,100, 200, 400 and $800 \mathrm{mg} / \mathrm{kg}$ dosage per day for 14 consecutive days. Group F rats which served as control were administered DMSO in physiological saline for 14 consecutive days. All the animals were further monitored for two weeks after the last administration.

At the end of the experimental period, the animals were sacrificed by decapitation and blood samples were collected without anticoagulant. The serum obtained was used for biochemical analysis of Aspartate amino transaminase (AST), Alanine amino transaminase (ALT), Alkaline phosphatase (ALP), Glucose, total protein, urea, sodium and potassium, using standard kits. Another blood samples were collected into the EDTA containers for the analysis of Packed Cell Volume (PCV) by the microhaematocrit method, haemoglobin concentration by cyanomethaemoglobin method, red blood cell (RBC) count, Total and differential leucocytes 
(WBC) count by the haemocytometer methods (Schalm et al., 1975). After obtaining the weight of all the organs, they were quickly transferred into $10 \%$ buffered formalin and examined grossly. Thereafter, the liver and kidney devoid of fat deposits from each of the treated groups and control are processed for histopathological studies.

\section{1) Acute Toxicity Studies}

\section{Results}

In the first phase of the acute toxicity studies, there were no remarkable signs of toxicity observed at 10 $\mathrm{mg} / \mathrm{kg}$ dosage, while at 100 and $1000 \mathrm{mg}$ dosages, there were however salivation, rubbing at site of application, nose and mouth on the floor of the cage and restlessness. In the second phase of the study, the signs of toxicity observed were same and more severe than those observed at the phase one. However, at 2900 and $5000 \mathrm{mg} / \mathrm{kg}$ dosages, all the animals died 2 hours after the extract administration and all survived at $1600 \mathrm{mg} / \mathrm{kg}$ dosage. Therefore the median lethal $\left(\mathrm{LD}_{50}\right)$ dose was calculated to be $2100 \mathrm{mg} / \mathrm{kg}$ dosage as geometric means on the doses for which there is zero mortality (0/3) and total mortality (3/3) i.e. between 1600 and $2900 \mathrm{mg} / \mathrm{kg}$.

Table 1: Acute Toxicity Assay Using Mice

\begin{tabular}{ccc} 
Groups & Dose $(\mathrm{mg} / \mathrm{kg}$ body weight $)$ & No. of Dead/Survived mice \\
\hline Control & $0.4 \mathrm{ml}$ of DMSO & $0 / 3$ \\
1 & 10 & $0 / 3$ \\
2 & 100 & $0 / 3$ \\
3 & 1000 & $0 / 3$ \\
4 & 1600 & $0 / 3$ \\
5 & 2900 & $3 / 3$ \\
6 & 5000 & $3 / 3$ \\
\hline
\end{tabular}

\section{2) Changes in Total and Percent Organ / Body Weight Ratio in acute toxicity of T. procumbens}

Throughout the period of observation, there was a significant gain in the total body weight with highest increase found in group that received lowest dose level of $50 \mathrm{mg} / \mathrm{kg}$ body weight and lowest increase is in $1600 \mathrm{mg} / \mathrm{kg}$ when compared with their baseline data $(\mathrm{P}<0.05)$. There was a significant increase in the body weight of the control compared to groups that were treated with the extract at 100,1000 and $1600 \mathrm{mg} / \mathrm{kg}$ body weight (Figure 1). Spleen recorded a general increase in the percent organ/body weight ratio with highest increase of $42 \%$ found in the $1000 \mathrm{mg} / \mathrm{kg}$ treated group. Both the liver and lungs recorded highest \%organ/body weight ratio of $12.3 \%$ and $18.1 \%$ respectively when compare to the control at $100 \mathrm{mg} / \mathrm{kg}$ body weight (Figure 3). The heart decreased at all the dose levels while the kidney enlarged at 10 and $1600 \mathrm{mg} / \mathrm{kg}$ body weight.

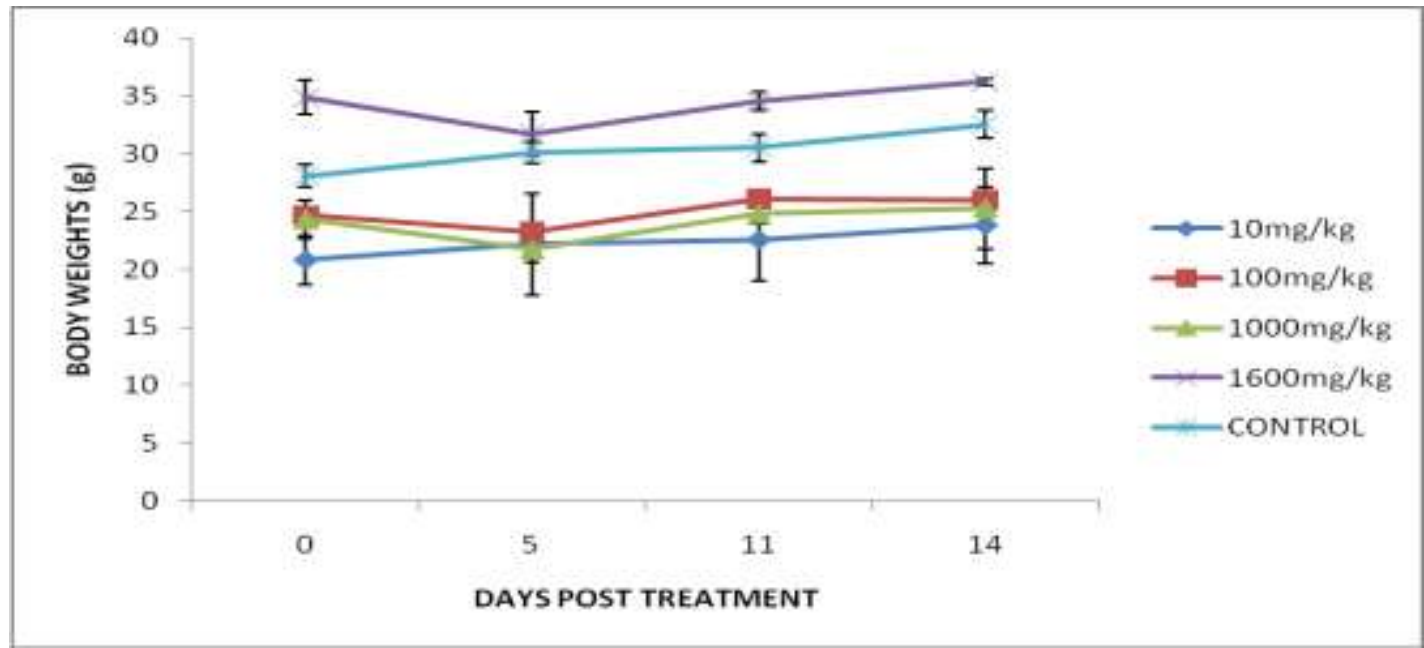

Figure 1: Changes in Body Weight of Mice Treated Acutely with T. Procumbens 


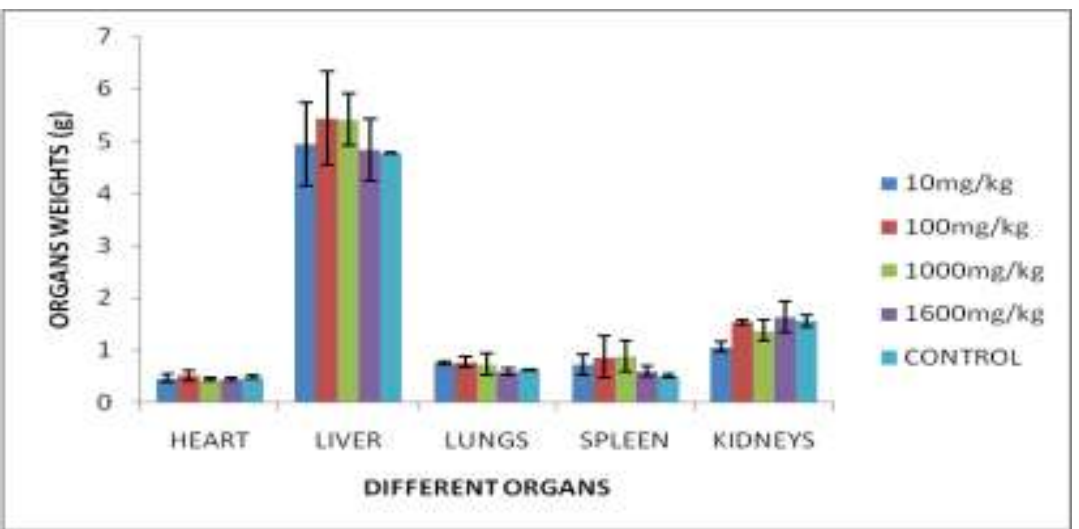

Figure 2: Changes in Organ Weight (g) of Mice Treated Acutely with T. Procumbens

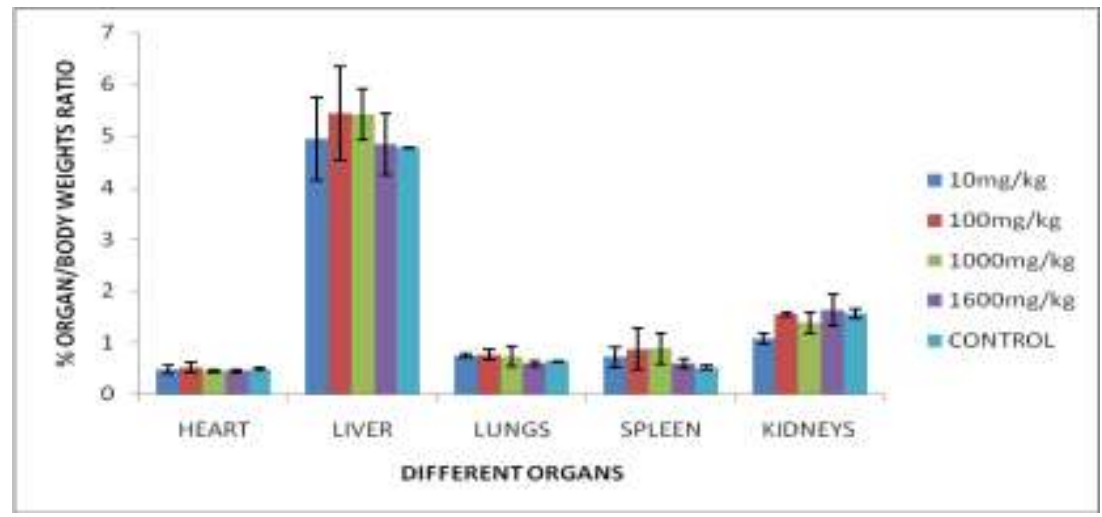

Figure 3: Changes in Percent Organ / Body Weight Ratio of Mice Treated Acutely with T. Procumbens

\section{3) Short Term Toxicity Studies}

\subsection{1) Changes in Total and Percent Organ / Body Weight Ratio}

Administration of T. procumbens at all the dose levels resulted in significant increase in the total body weight as compared to that of pre-treatment data $(\mathrm{P}<0.05)$. Among the treated groups, the highest weight increase was observed in $800 \mathrm{mg} / \mathrm{kg}$ treated group, where the body weight increased by $47.5 \%$ of the pretreatment value (Figure 4).

Similarly, there was increase in percent organ/body weight ratio of liver and spleen in a dose dependant pattern, with highest increase in liver found in the group that received lowest dose $(\mathrm{P}<0.05)$. However, the kidneys, heart and lungs were not significantly affected when compared to the untreated control group $(\mathrm{P}>0.05)$. At $50 \mathrm{mg} / \mathrm{kg}$ body weight, the $\%$ organ / body weight ratio of liver recorded $17 \%$ while that of spleen was $61 \%$ increased as compared to the untreated control. These observations are the same with the changes in organ weight (Figures 5 and 6).

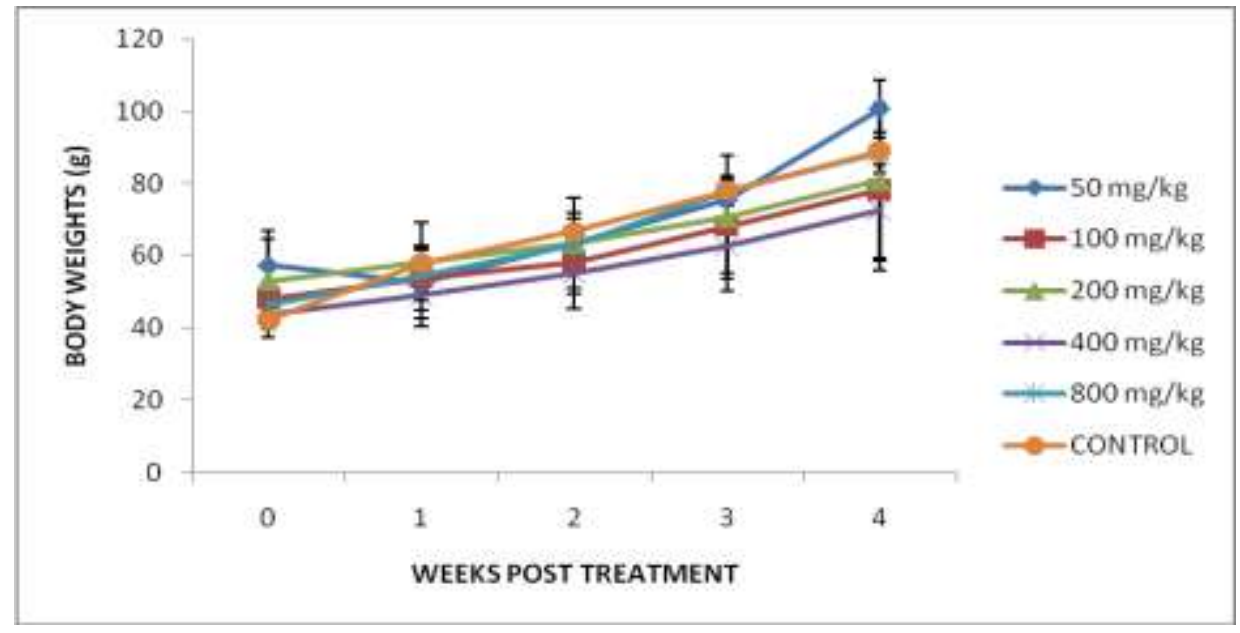


Figure 4: Changes in Body Weight of Rats Treated with T. procumbens Ethyl acetate extract at Short Term Toxicity Studies

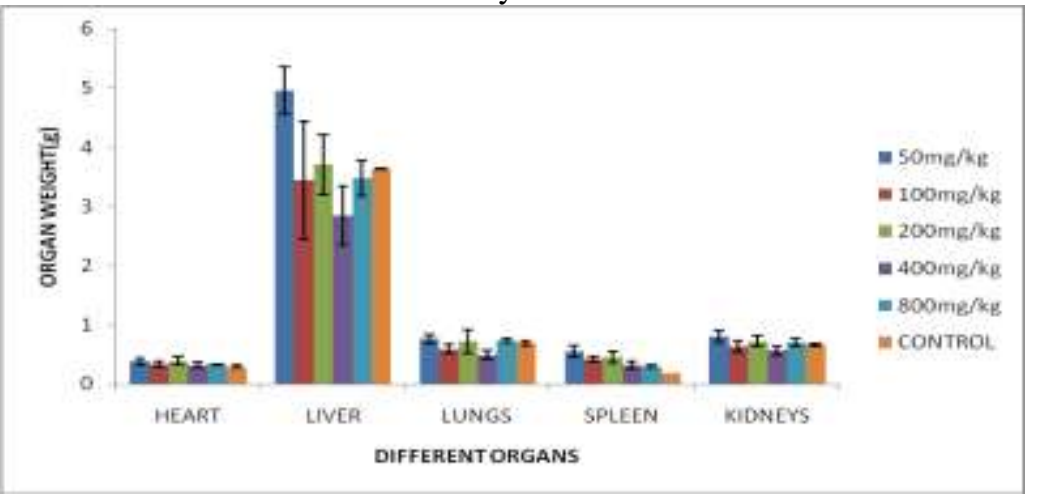

Figure 5: Changes in Organ Weight of Rats Treated with T. procumbens at Short Term Toxicity Studies

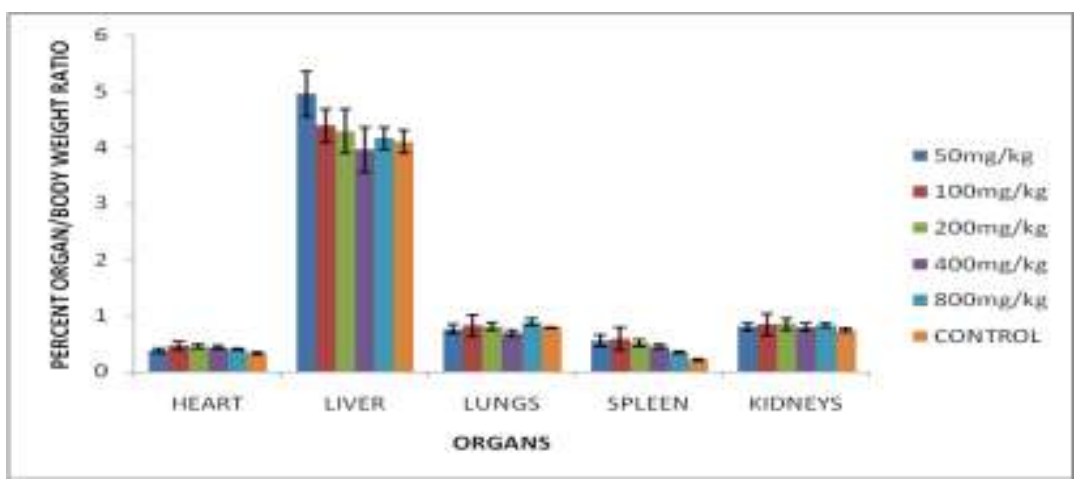

Figure 6: Percent Organ / Body Weight Ratio of Rats Treated with T. procumbens at Short Term Toxicity Studies

\subsection{2) Haematological Changes in Rats}

The packed cell volume (PCV), lymphocyte and RBC counts increased particularly with groups treated at 400 and $800 \mathrm{mg} / \mathrm{kg}$ body weight $(\mathrm{P}>0.05)$. However, the increase in WBC counts and Neutrophils were dose dependent but not statistically significant $(\mathrm{P}>0.05)$.

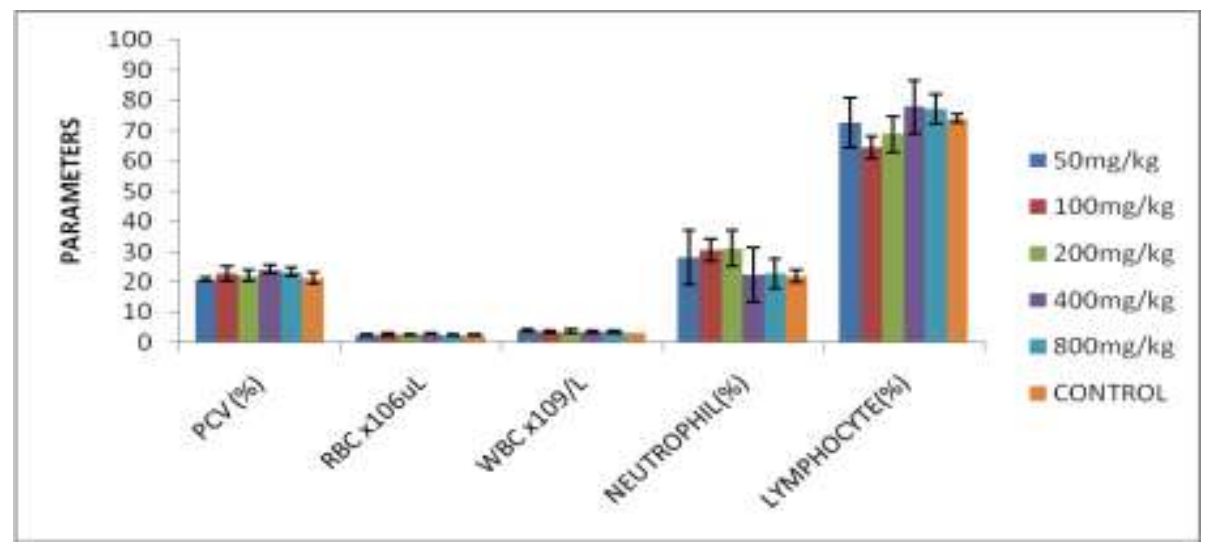

Figure 7: Haematological Changes of Rats Treated with T. procumbens

\subsection{3) Biochemical Changes in Rats}

With the exception of the lowest dose administered, all the other doses resulted in a significant decrease in glucose levels $(\mathrm{P}<0.05)$. Similarly there is significant increase in ALT and decrease in AST with $800 \mathrm{mg} / \mathrm{kg}$ producing highest effect $(\mathrm{P}<0.05)$. However, the urea and electrolyte levels increase slightly $(\mathrm{P}>0.05)$, while ALP, total protein, $\mathrm{Na}^{+}$and $\mathrm{K}^{+}$were not affected significantly $(\mathrm{P}>0.05)$ at all the dose levels (Table 2). 


\begin{tabular}{|c|c|c|c|c|c|c|}
\hline Parameters & $50 \mathrm{mg} / \mathrm{kg}$ & $100 \mathrm{mg} \mathrm{kg}$ & $200 \mathrm{mg} / \mathrm{kg}$ & $400 \mathrm{mg} \mathrm{kg}$ & $800 \mathrm{mg} \mathrm{kg}$ & Control \\
\hline AsT $(\pi U / L)$ & $12.99=1.5$ & $2.07 \pm 3.4$ & $5.75=19$ & $7.43=2.8$ & $2.22 \pm 0.8$ & $14.73=3$ \\
\hline$A I T(I U / L)$ & $67.36+4.4$ & $90,39-7.1$ & $64.98-5.8$ & $61.00=0.6$ & $50.10+0.5$ & $39.78-0.2$ \\
\hline AIP (IL:L) & $75.23=6,4$ & $70.31=2.7$ & $74.35=3.5$ & $75.33=3.8$ & $76.28=5.2$ & $74,67=6.4$ \\
\hline UREA (mस0)/L) & 8. $72=0.6$ & s. $85 \neq 0.8$ & $7.41=0.9$ & $7.70=0.6$ & $8.80=1.2$ & $6.73=1.0$ \\
\hline Total Protein $(\mathrm{g} / \mathrm{L})$ & $0.68+0.5$ & $9.96+0.7$ & $6.10-0.3$ & $6.13+0.3$ & $0.91+0.4$ & $6.47 \omega 0.2$ \\
\hline $\begin{array}{l}\text { OLUCOSE } \\
\text { (mInSLI) }\end{array}$ & $7.56 \pm 1,1$ & $5.26 \pm 2,7$ & $4.8 .4=3.1$ & $3.73=1.3$ & $2.81=0.2$ & s. $17 \pm 1.6$ \\
\hline $\mathrm{Na}^{-}($cramall $\mathrm{L})$ & $125.21-5.0$ & $128.18+3.5$ & $130.33+6.2$ & $132.17=0.4$ & $13.4 .01-3.7$ & $126.00+5.0$ \\
\hline 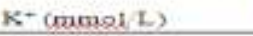 & $5.50 \pm 0.8$ & $5.46 \pm 0.3$ & $5.65 \pm 0.1$ & $6.20 \pm 0.9$ & $6: 81 \pm 0.5$ & $5.13 \pm 0.1$ \\
\hline
\end{tabular}

Values are means of three determinations $( \pm S D)$

\subsection{4) Histopathological Studies of Rat Liver and Kidney}

There was a general deposition of haemosiderin in the liver of treated animals which was dose dependant. The deposition of haemosiderin was highest in $800 \mathrm{mg} / \mathrm{kg}$ body weight and lowest in $50 \mathrm{mg} / \mathrm{kg}$ dosage (Plate II). The section of the control showed a remarkable normal liver tissue with a well preserved hepatic architecture (Plate I). The liver of $50 \mathrm{mg} / \mathrm{kg}$ treated rats showed a sporatic infilteration of the liver parenchyma cells and haemosiderin was absent. In addition the changes in liver tissues were not pronounced (Plate II). At $100 \mathrm{mg} / \mathrm{kg}$ body weight, there was mild infiltration of inflammatory cells (WBC) and haemosiderin deposition was insignificant. There were inflammation and infiltration of liver, (pericortal inflammation), as evidenced by numerous polymorphonuclear leucocytes, while the haemosiderin deposition was also fewer in the liver of rats treated at $200 \mathrm{mg} / \mathrm{kg}$ dosage (Plate III). Similarly, the liver section of rats treated at 400 and $800 \mathrm{mg} / \mathrm{kg}$ dosage showed old haemorhage as indicated by haemosiderin deposit throughout the entire liver parenchyma. The glomerular apparatus and tubules of the control rat kidney were visible (Plate IV). At 50 $\mathrm{mg} / \mathrm{kg}$ body weight there were mild interstitial haemosiderin deposition and occasional intra-glomeruli bleeding (Plate V). There was foci glomeruli haemorrhage in addition to interstitial haemosiderin deposition in kidney of rat treated at $100 \mathrm{mg} / \mathrm{kg}$ dose level. At $200 \mathrm{mg} / \mathrm{kg}$ dosage, the interstitial haemorrhage as evidenced by collection of haemosiderin laden macrophage was observed (Plate VI). Similar interstitial haemosiderin deposition signifying interstitial haemorrhage with glomerular extravasation of RBC was also seen in other kidneys dosed at 400 and $800 \mathrm{mg} / \mathrm{kg}$ treated rat.

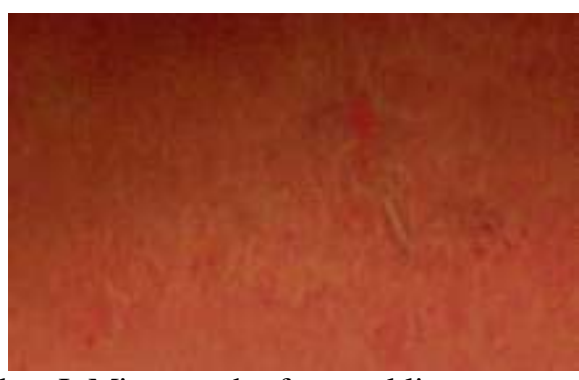

Plate I: Micrograph of normal liver extract untreated control group (X 100).

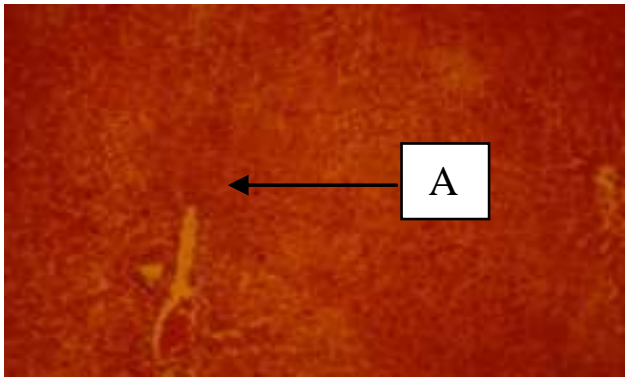

Plate II: Micrograph of rat liver tissue Treated tissue of at $50 \mathrm{mg} / \mathrm{kg}$ body weight (X 100).

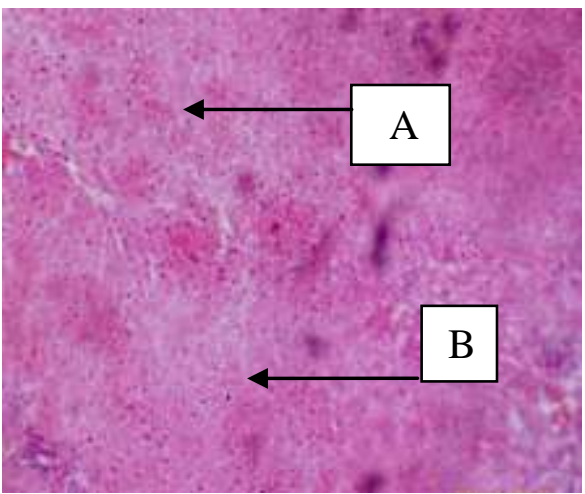


Plate III: Micrograph of rat liver treated at $200 \mathrm{mg} / \mathrm{kg}$ with numerous polymorphonuclear (A) leucocyte and fewer haemosiderin (B)

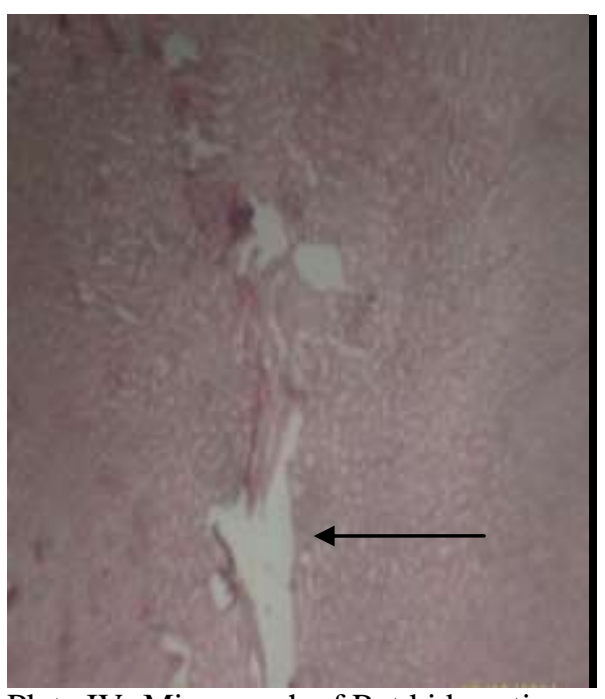

Plate IV: Micrograph of Rat kidney tissue of

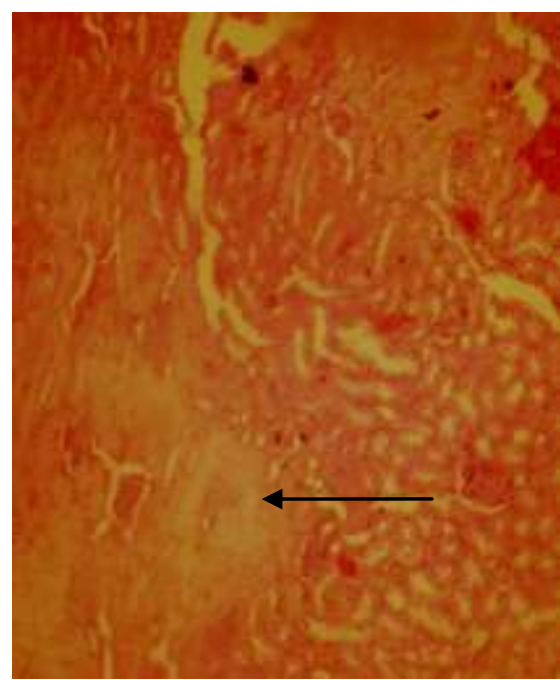

PLATE V: Micrograph of Rat kidney

the control group (X 100). Normal glomerular Tissue treated at 50mg/kg showing mild apparatus and tubules are visible (arrows) interstitial haemosiderin deposit (arrow)

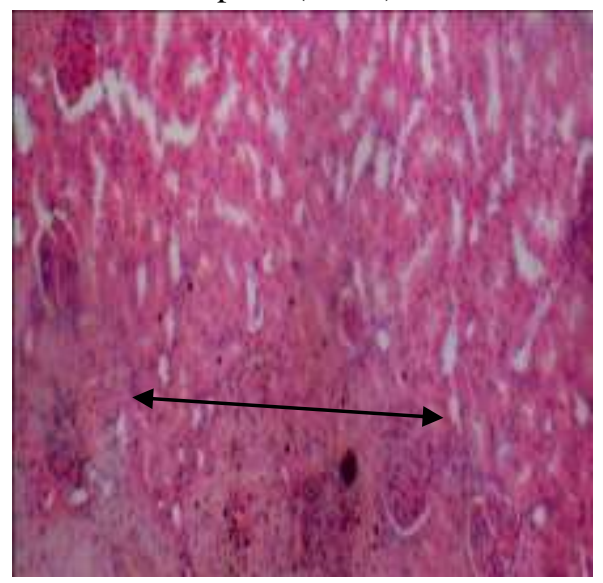

PLATE VI: Micrograph of Rat kidney tissue treated at $200 \mathrm{mg} / \mathrm{kg}$ showing mild interstitial haemorrhage with haemosiderin laden macrophage deposit (arrow)

\section{Discussion}

The result of acute toxicity was based on intraperitoneal administration where the compound in the extract was directly transported through the blood circulation to the target organ to exert their toxic effect. However, if the administration was oral, the $\mathrm{LD}_{50}$ may be much higher since the extract will undergo metabolism to a new product which could be less or not toxic. According to Lorke (1983), substances more toxic than $1 \mathrm{mg} / \mathrm{kg}$ are so highly toxic that it is not so important to calculate the $\mathrm{LD}_{50}$ exactly while $\mathrm{LD}_{50}$ values greater than $5000 \mathrm{mg} / \mathrm{kg}$ are of no practical interest. Hence, the $\mathrm{LD}_{50}$ of $2100 \mathrm{mg} / \mathrm{kg}$ body weight is an indication that the extract may be harmful when administered intraperitoneally. Investigation of the acute toxicity is the first step in the toxicological investigation of an unknown substance. The index of acute toxicity is the $\mathrm{LD}_{50}$.

Results from short term toxicity studies of the crude ethyl acetate extract of T. procumbens indicated that the liver of test animals were significantly affected at all the dose levels. There was a significant increase in ALT and decrease in AST activities $(\mathrm{P}<0.05)$. The reduction in the serum AST activity following administration of the extract may be attributed to the reduced rate of synthesis in the liver. The rise in the ALT activity may imply that the administration of the extract has resulted in hepatocellular damage that lead to the leakage of these enzymes into circulation. The administration of the extract did not produce significant increase in the ALP activity $(\mathrm{P}>0.05)$. Since, ALP hydrolyses phosphate monoesters, non increase of this enzyme may not constitute 
a threat to the life of the cells that are dependent on a variety of phosphate esters for their vital process, as increase in the activity of this enzyme may lead to indiscriminate hydrolysis of phosphate ester metabolite of the liver, an important biochemical symptom of cytolysis. AST and ALT are normally localised within the cells of the liver, heart, kidney, muscles and other organs. The enzymes are of major importance in assessing and monitoring liver cytolysis (Wada and Snell, 1962). Their presence in the serum may give information on organ dysfunction (Wells et al., 1986). ALT is very specific for hepatic tissue and is much more sensitive to hepatic damage and levels rise higher than those of the AST in most type of hepatocellular damage. The measurement of the activities of marker or diagnostic enzymes in tissue plays a significant and well known role in diagnosis, disease investigation and in the assessment of drug or plant extract for safety/toxicity risk. The enzymes considered in this study are useful marker enzymes of liver cytolysis and damage of the liver cells (Schmidt and Schmidt, 1979). Although the increment in the serum levels of $\mathrm{Na}^{+}, \mathrm{K}^{+}$and urea as compared to control is not significant, there is an indication that the kidneys were spared from any damage and so maintained their integrity (Table 2). Measurement of plasma $\mathrm{Na}^{+}, \mathrm{K}^{+}$, and $\mathrm{HCO}_{3}{ }^{-}$usually accompanied by plasma urea or creatinine and sometimes $\mathrm{Cl}^{-}$concentrations together make up the most frequently requested group of test for kidney function (Whitby et al., 1988). The principal univalent cations in the extracellular fluid (ECF) and intracellular fluid (ICF) are $\mathrm{Na}^{+}$and $\mathrm{K}^{+}$respectively (Whitby et al., 1988). The concentrations of proteins may be altered both in diseases that primarily affect protein metabolism and in diseases where there is dehydration or overhydration (Whitby et al., 1988). Most diseases that alter plasma proteins affect the synthesis of proteins in the liver, or the distribution of or their rate of catabolism or rate of excretion (Whitby et al., 1988). Therefore, the intraperitoneal administration of $T$. procumbens extract to rats as compared to control animals did neither affect protein synthesis nor it's rate of excretion since values obtained were not significant between the test and control $(\mathrm{P}>0.05)$. The administration of crude extract of $T$. procumbens to experimental rats resulted in a significant reduction of glucose levels in a dose dependant manner with highest dose having highest effect $(\mathrm{P}<0.05)$. Glucose is one of the clinically important carbohydrates. Disorders of carbohydrate metabolism such as diabetes are evaluated in part by measurement of plasma glucose in either the fasting state or after suppression or stimulation. The significant decrease in glucose levels in the test group implies that the extract may serve as a good source for antidiabetic agent. In addition, any parasitic infection that largely dependent on glucose for survival like in trypanosomiasis can be deprived of this important nutrient and therefore may also serve as source of treatment for the host.

In the haematological analysis, the measurement of PCV and RBC count can be used as a simple screening test for anaemia. Anaemia is an absolute decrease in the total number of RBC per $\mathrm{ml}$ of blood, decrease in PCV due fewer RBC. With the exception of group treated lowest tested dosage, where there was a decrease in the value, although not significant $(\mathrm{P}>0.05)$, the PCV and RBC count increased at all other dose levels. This means that administration of ethyl acetate extract of $T$, procumbens may be beneficial in anaemia related disorder particularly in trypanosomiasis. Similarly, there was general increase in total white blood cell (leucocytes) and lymphocyte counts. The entire system of WBC focuses on host defence while the lymphocytes are essential to immune defense system as their primary function is to respond to antigens by initiating the immune response (Odutola, 2000). The increases observed in WBC and lymphocyte is a further confirmation of earlier report that $T$. procumbens influenses both humoral as well as cell mediated immune system Vis a vis assists in genesis of imroved antibody response against specific clinical antigen (Tiwari et al., 2004). Slight increase in neutrophils was also observed in the test group when compare with the control group $(\mathrm{P}>0.05)$. Neutrophilia is most frequently caused by systemic or severe local bacterial infection where their primary role is in immunity against bacterial and fungal infection by phagocytosis (Odutola, 2000). Neutrophils, also known as Granulocytes or segmented neutrophils, are the main defender of the body against infection and antigens. High levels may indicate an active infection; a low count may indicate a compromised immune system or depressed bone marrow (low neutrophil production). Therefore administration of this extract may be of help in the presence of a clinical antigen like trypanosomes.

It has been recommended that body weight be measured atleast once a week during toxicity studies. This is because body weight is one of the most sensitive indicators of the condition of an animal if it is monitored frequently and carefully during a study (Wilson et al., 2001). Rapid and/or marked body weight loss is usually a harbinger of ill health or death. Rapid body weight loss can be due to either decreased feed or water consumption, disease or specific toxic effect (Wilson et al., 2001). Collection of terminal body weight and organ weights for all animals during necropsy is normal practise in repeated dose toxicity studies (Wilson et al., 2001).

The effect of the extract can further be deduced from the body weight status of the animals at all the dose levels. The percent organ/body weight ratio during the acute toxicity studies were higher at low dosages than the groups treated with the extract at high dosages. This observation is also similar during the short term toxicity studies. Hence there was observed enlargement of both the liver and kidneys when compared to the untreated control. These indicated that animals administered with $T$. procumbens at low dosage were in a better 
physical state to eat more than those in the higher dosage groups of 1000-1600 for acute toxicity and 200$800 \mathrm{mg} / \mathrm{kg}$ body weight short term toxicity studies.

The specific toxic effect of this extract particularly at high dose level corroborated the result of histopathology where there was haemosiderin deposition. In histopathology, generally there was old haemorrhage indicated by haemosiderin deposition throughout the entire liver and kidney tissues. In kidney tissue, there was interstitial haemosiderin deposition signifying interstitial haemorrhage as evidence by collection of haemosiderin laden macrophages particularly at $100-400 \mathrm{mg} / \mathrm{kg}$ body weight. It was observed that the amount of haemosiderin deposition depend on dose level with highest dose level producing highest haemosiderin deposition. Since the PCV value did not fall when compared with the control, this implied that the destruction of red blood cells and endothelial of blood vessel might not be massive and hence anaemia could not have resulted because of administration of $T$. procumbens extract. The high amount of macrophages was observed from the kidneys which meant that the extract had the ability to stimulate the immune reaction through the production of antibodies. Earlier study has shown that the T. procumbens influences both humoral as well as cell mediated immune system (Tiwari et al., 2004) and therefore the extract of this plant may be useful in infections where the immune system is compromise.

\section{Conclusion}

The administration of Tridax procumbens was moderately toxic at $2100 \mathrm{mg} / \mathrm{kg}$. It had the ability to stimulate high amount of macrophages production and may be useful in infections where the immune system may be compromise. Studies of this kind are always needed before a phytotherapeutic agent can be generally introduced.

\section{Acknowledgement}

The authors are grateful to Muhammad Dangana for preparing the buffered formalin and Yohana Auta for viewing and snapping the tissue slides. They are staff of Federal University of Technology, Minna, Niger state, Nigeria. This work was funded by a research grant from Nigerian Institute for Trypanosomiasis Research to Abubakar A. with thanks.

\section{References}

[1] Bass NM, Ockner BA.( 1996) Drug-induced liver disease, In: Zakin D, Boyer TD, eds. Hepatology: a textbook of liver disease, 3rd eds. Philadelphia: WB Saunders,; 962-1017.

[2] Deng JF.( 1994). Clinical Toxicity of Herbal Medicine in Taiwan, 7th International Conference on Health Problems Related to the Chinese.

[3] Diwan P. V., Karwande I., Margaret I. and Sattar P. B. (1989). Pharmacology and biochemical evaluation of Tridax procumbers on inflammation. Indian journal of pharmacology 21. Pp $1-7$.

[4] Emily M (2007). Toxicity. In: Encyclopedia of Earth. Eds. Cutler J. Cleveland, Washington D.C.

[5] Lorke, D., (1983). A new Approach to Practical Acute Toxicity testing. Archives of Toxicoloogy; 54:275 - 287.

[6] Odutola A. A. (2000). In: Rapid interpretation of routine clinical laboratory tests. Publisher: S.Asekome and Company. Pp 42-52

[7] Ogbadoyi, E.O., Hafsatu, B., Adamu. Y. K., Chinenye. E. N., Solomon, I., Rasheedat, B.A., Emmanuella, I.O., Paul, B.M., Akinsunbo, A.O and Theophilus, Z.A (2007)b. Preliminary Studies of Antitrypanosomal Properties of Selected Nigerian Medicinal Plants. Journal of Research in Bioscience., 3 (3):38-43.

[8] O'Hara M, Kiefer D, Farrel K, Kemper K. (1998). A review of 12 commonly used medicinal herbs. Arch Fam Med; $523-536$. Pathak AK, Saraf S, Dixit VK (1991). Hepatoprotective activity of Tridax procumbens - Part I. Fitoterapia; 62:307-13.

[9] Saraf S, Pathak AK, Dixit VK. (1991) Hair growth promoting activity of Tridax procumbens . Fitoterapia;62:495-8.

[10] Schalm, O.W., Jain, N.C. and Carrol, E.J. (1975). Veterinary haematology. $3^{\text {rd }}$ edn. Philadelphia, Lea and Febiger, 807p.

[11] Shri JNM. (2003). Ginger: It's Role in Xenobiotic Metabolism, ICMR Bulletin; 33(6): 57-63.

[12] Taddei A. and Rosas R. A. J. (2000). Bioactivity studies of extracts from Tridax procumbers Phytomedicine 7: $235-238$.

[13] Tiwari U., Rastigi B., Singh P., Saraf D.K. and Vyas S.P. (2004). Immunomodulatory effects of aqueous extract of Tridax procumbens in experimental animals. Journal of Ethnopharmacology, Vol 92, Issue 1,Pages 113-119

[14] Tyler VE.( 1994). Herbs of Choice. The Therapeutic Use of Phytomedicinals, Binghamton NY: Haworth Press Inc.

[15] Udupa S. L., Udupa A. L. and Kulkarni D. R. (1991). Influence of Tridax procumbers on lysyl oxidase activity and wound healing. Planta Medica 57:525 - 327.

[16] Wada, H and Snell, E. E. (1962). Enzymatic transamination of ptridoxamine-pyruvate transaminase. J. Biol. Chem. 237: 133-137

[17] Wells, R. M., McIntyre, R. H., Morgan, A. K and Davies, P. S. (1986). Physiological stress responses in big game fish after exposure: observation on plasma chemistry and blood factors. Comp. Biochem. Physiol. 64A: 565-571

[18] Whitby, L. G., Smith, A. F. and Beckett, G. J. (1988). In: Lecture note on Clinical Chemistry. Oxford Blackwell Scientific Publications, London, Edinburgh, Boston, Melbourne, Paris, Berlin, Vienna. Pp 38-62.

[19] Wilson N. H., Hardisty, J. F. and Hayes, J. R. (2001). Short Term, Subchronic, and Chronic Toxicology Studies. In: Principles and Methods of Toxicology, Fourth Edition, Edited by A. Wallace Hayes, Tylor and Francis. Philadelphia.

[20] Wright, P. J and Plummer, D. T (1974). The use of urinary enzyme measurement to detect renal damages caused by nephrotoxic compounds. Biochem. Pharmacol. 12: 65

[21] Zbinden G, Flury-Roversi M.( 1981). Significance of the LD50 test for the toxicological evaluation of chemical substances. Arch Toxicol; 4792: 77. 